\title{
Facet tropism: possible role in the pathology of lumbar disc herniation in adolescents
}

\author{
Honggang Wang, MD, and Yue Zhou, MD, PhD \\ Department of Orthopedics, Xinqiao Hospital, Third Military Medical University, Chongqing, China
}

\begin{abstract}
OBJECTIVE The role of facet tropism (FT) in lumbar disc herniation (LDH) is ambiguous. The present study aimed to investigate the association between FT and LDH in adolescents.

METHODS This study included 65 adolescents with LDH with 1- or 2-level LDH, or both. Facet angles were measured with MRI. FT was defined as asymmetry of $10^{\circ}$ between the left and right side. The same levels of 30 healthy persons who had no lumbar lesions were used as controls. Statistical analysis was performed using the chi-square test.
\end{abstract}

RESULTS FT was identified in 16 of 39 patients with LDH in L4-5 and in 3 of 30 controls ( $p=0.006,0 R 6.261,95 \% \mathrm{Cl}$ 1.619-24.217). It was also identified in 12 of 27 patients with LDH in L5-S1 and in 4 of 30 controls ( $p=0.017,0 R 5.200$, $95 \% \mathrm{Cl} 1.420-19.039)$. One patient had LDH in both L4-5 and L5-S1.

CONCLUSIONS FT is associated with LDH in both L4-5 and L5-S1 levels in adolescents.

http://thejns.org/doi/abs/10.3171/2015.7.PEDS15175

KEY WORDS lumbar disc herniation; facet joint; facet tropism; adolescents; spine

$\mathrm{L}$ UMBAR disc herniation (LDH) is a common reason for low-back pain and lower-extremity radicular pain. LDH is prevalent in elderly people, but extremely rare in adolescents. According to previous reports, the incidence of LDH in pediatric and adolescent populations varies from $1 \%$ to $5 \%$ in those who are 20 years old or younger. . $^{18,21,27}$

Facet orientation is an important structural factor for degenerative disc diseases. ${ }^{3}$ Facet tropism (FT), defined as asymmetry between left and right facet joints, has the potential to alter the biomechanics of lumbar movements and expedite the degenerative changes either in the joint or adjacent intervertebral discs. ${ }^{26}$ The first hypothesis of Farfan et al. ${ }^{9}$ was that there is a relationship between FT and the development of LDH, but no final conclusion was made after clinical tests. ${ }^{4,5,12}$

Trauma is the main cause of LDH in adolescents, 2,22,25 which is different from that in adults. ${ }^{28}$ A recent finite element research study confirmed that FT could make the corresponding segment more vulnerable to external movements or anterior shear force..$^{15}$ Therefore, FT may play a more important role in the development of LDH in adolescents than in adults. In the present study, the authors investigated the association between FT and LDH in adolescents.

\section{Methods}

The study included 65 patients between 13 and 20 years of age with 1- or 2-level LDH, or both. All patients were treated at our institution from August 2011 to June 2014. The control group included 30 volunteers between 15 and 50 years of age who had no lumbar lesions; the inclusion criteria for the control group were similar sex distribution, similar labor intensity, and similar body mass index (BMI) to those in the LDH group. The exclusion criteria were having undergone previous lumbar spinal surgery, spinal malformation, spinal infection, and asymptomatic LDH (Table 1). 


\section{Operative Treatment}

All the patients underwent operative treatment for LDH. Exclusion criteria for the LDH group included patients with recurrent disc herniation, spina bifida associated spondylolisthesis, transitional vertebra, previous surgery, scoliosis, previous trauma, or spinal infection. All members of the LDH study and control groups underwent 1.5-T MRI (GE Healthcare) with a slice thickness of $4 \mathrm{~mm}$. The facet joint orientation was measured using a computer-aided design image tool in the cross section of the MR images that was parallel to the endplate and caudal to the intervertebral disc. We used the same measuring method as used by Chadha et al. ${ }^{5}$

\section{Facet Line Measurements}

The line drawn passing through the center of the disc and the center of the base of the spinous process was defined as the reference plane, and the line drawn between the anteromedial and posterolateral edges of the bilateral superior articular facets was defined as the facet line. The angle between the 2 lines was the facet joint angle (Fig. $1[\alpha$ and $\beta]$ ). FT was defined as asymmetry of $10^{\circ}$ between the left and right sides. ${ }^{5}$ We measured the left and

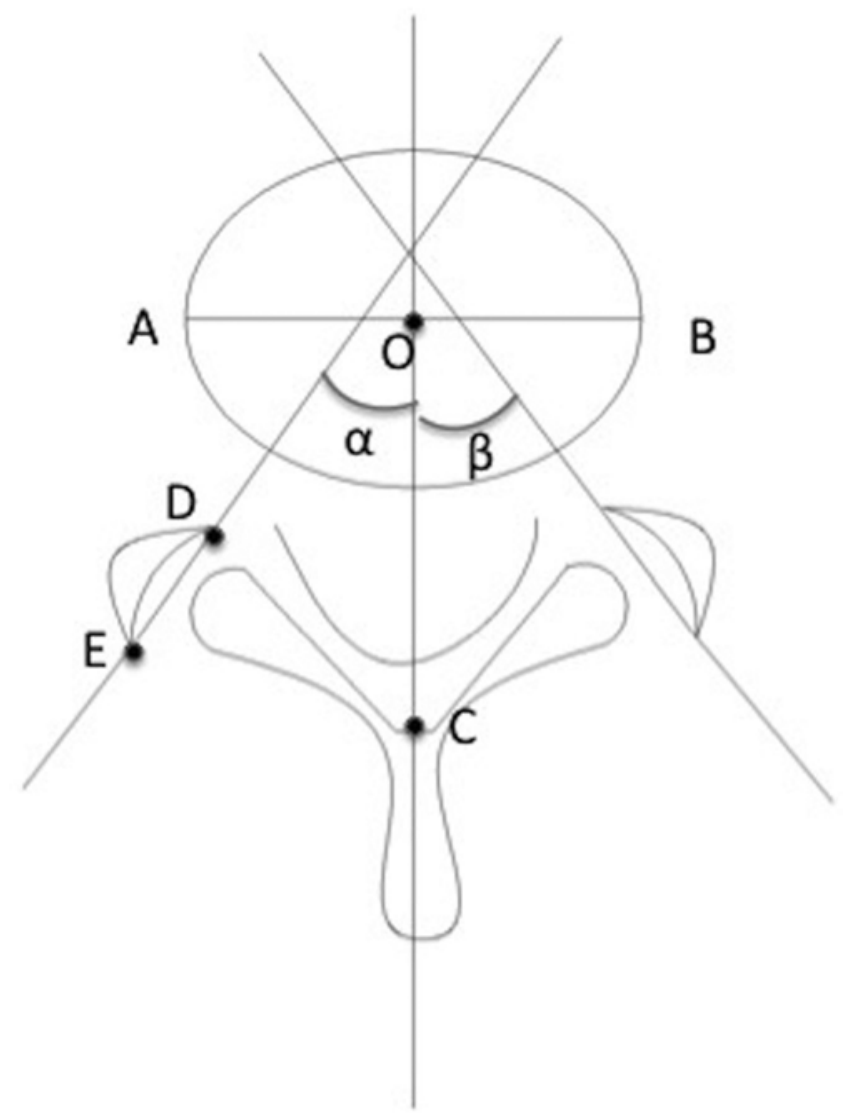

FIG. 1. Diagram of the method used to measure the facet joint angle. The facet line is drawn between the 2 peaks of each of the superior articular facets ( $D$ and $E$ ). The midline is drawn through the center of the lumbar vertebral body $(\mathrm{O}, \mathrm{AO}=\mathrm{OB})$ and the middle point of the base of the spinous process (C). The angle between the midsagittal line and facet line was measured for each side of the lumbar vertebral body $(\alpha=$ right facet angle, $\beta=$ left facet angle). right facet angle in the cross section of the herniated level (Fig. 2); the facet angles of the same level in the controls were also measured (Fig. 3). To avoid measurement errors, 2 spine surgeons without knowledge of the patients' symptoms and the purpose of the study measured the facet angle independently. The intraclass correlation coefficient was used to identify the reliability of 2 groups of facet angles measured by the 2 observers. The average value of the 2 observers' data was used for the analysis.

\section{Statistical Analysis}

Statistical analysis was performed using the chi-square test. A significance level of 0.05 was used. The odds ratio (OR) was used to determine the association between FT and LDH. All the analyses were performed using SPSS for Windows (version 13.0, SPSS, Inc.).

\section{Results}

The study included 65 patients with LDH and 30 controls (Table 1). In the LDH study group, 38 patients had LDH at the L4-5 level, 26 at L5-S1, and 1 had LDH at both L4-5 and L5-S1; none had LDH at L3-4. Forty patients had herniation toward the left side, 11 toward the right side, and 15 in the middle. One patient had herniation in 2 segments; therefore, 66 segments were present in 65 patients.

The intraclass correlation coefficient was found to be 0.964 , which meant that there was a similarity in the facet joint angle measurement between the 2 observers. The facet angle was measured at 285 levels from L3-4 to L5S1 in 65 patients and 30 controls. In the study patients, 28 FTs (42.4\%) were found in $66 \mathrm{LDH}$ segments (Fig. 2), compared with 7 FTs (11.7\%) in 60 segments with no LDH in the controls. A highly significant association was found between FT and LDH overall, according to the chi-square test $(\mathrm{p}=0.000$, OR $5.579,95 \%$ confidence interval $[\mathrm{CI}]$ 2.208-14.099; Table 2).

The associations between FT and LDH were also
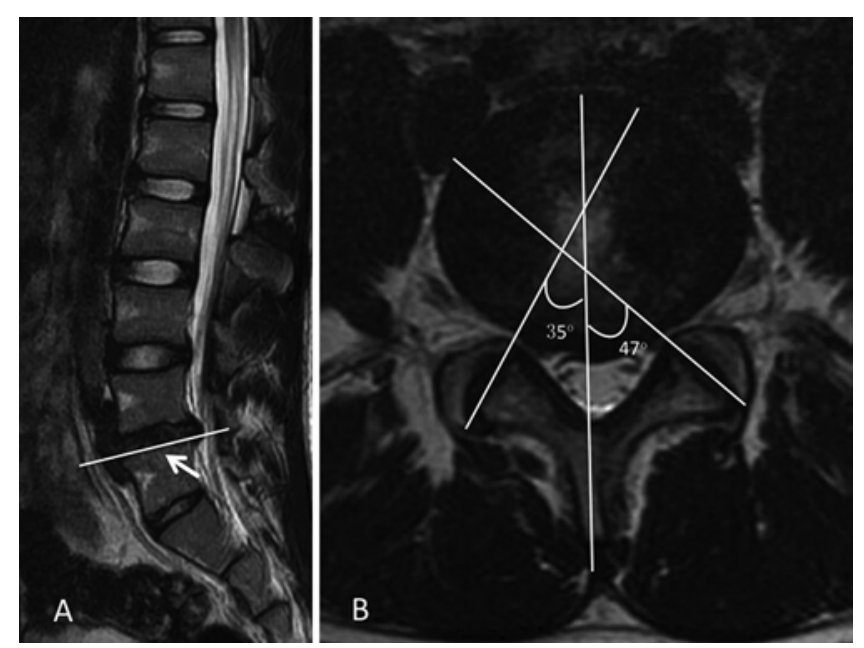

FIG. 2. MRI of patients with LDH in L4-5. A: Sagittal view of the lumbar spine. The arrow points to the line that indicates the location of the cross section. B: Cross section of L4-5. $\alpha=35^{\circ}, \beta=47^{\circ}$; FT was present at the L4-5 level. 

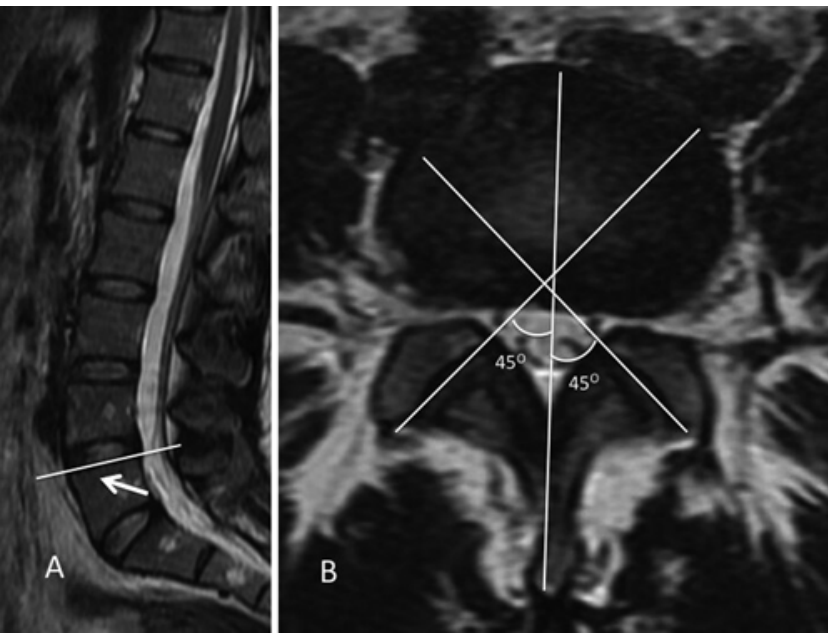

FIG. 3. MRI of patients with no LDH. A: Sagittal view of the lumbar spine. The arrow points to the line that indicates the location of the cross section. B: Cross section of L4-5. $\alpha=45^{\circ}, \beta=45^{\circ}$; no FT was present at the L4-5 level.

highly significant in both the L4-5 and L5-S1 segments, respectively, according to the continuity corrected chisquare test. FT was found in $16(41.0 \%)$ of 39 segments in patients with LDH in L4-5 compared with $3(10.0 \%)$ of 30 segments in controls $(\mathrm{p}=0.006$, OR $6.261,95 \% \mathrm{CI}$ 1.619-24.217; Table 2). In L5-S1, FT was in 12 (44.4\%) of 27 segments in patients with LDH compared with 4 $(13.3 \%)$ of 30 in controls ( $\mathrm{p}=0.017$, OR $5.200,95 \%$ CI 1.420-19.039; Table 2).

\section{Discussion}

The facet joint is an important structure in the posterior area of the spinal column. One study demonstrated that in the erect standing position, the facet joints absorb on average $16 \%$ of the body load, ${ }^{1}$ and in another study, these joints carried $3 \%-25 \%$ of the body load. ${ }^{29}$ The 2 facet joints may carry parallel loading in the normal lumbar spine. FT, defined as asymmetry in the left and right facet joint angle, can create an asymmetrical stress distribution in the zygapophysial tissues and intervertebral disc. ${ }^{6} \mathrm{Cy}-$ ron and Hutton concluded that the annulus fibrosus on the side with greater coronal orientation may suffer a higher compressive load as well as rotational stress. ${ }^{6}$ Such a loading imbalance may accelerate the degeneration of the facet joints and intervertebral discs. ${ }^{7}$

\section{TABLE 1. Summary of the demographics of the patients and} controls

\begin{tabular}{lcc}
\hline \multicolumn{1}{c}{ Characteristic } & LDH Group $(n=65)$ & Controls $(n=30)$ \\
\hline Mean age in yrs (range) & $17.96(13-20)$ & $40.56(15-50)$ \\
\hline Sex ratio (M/F) & $46 / 19$ & $21 / 9$ \\
\hline Mean BMl (range) & $25.1(18.2-30.5)$ & $25.3(19.0-30.2)$ \\
\hline Herniation level & & \\
\hline L4-5 & 38 & None \\
\hline L5-S1 & 26 & None \\
\hline L4-5 \& L5-S1 & 1 & None \\
\hline
\end{tabular}

TABLE 2. Association of facet tropism in patients (LDH) and controls

\begin{tabular}{cccccc}
\hline \multirow{2}{*}{ Level } & Group & $\begin{array}{c}\text { Tropism } \\
\text { Present }\end{array}$ & $\begin{array}{c}\text { Tropism } \\
\text { Absent }\end{array}$ & $\begin{array}{c}p \\
\text { Value }\end{array}$ & OR (95\% Cl) \\
\hline L4-5 & LDH & 16 & 23 & 0.006 & $6.261(1.619-24.217)$ \\
\cline { 2 - 4 } & Controls & $3^{*}$ & 27 & & \\
\hline \multirow{2}{*}{ L5-S1 } & LDH & 12 & 15 & 0.017 & $5.200(1.420-19.039)$ \\
\cline { 2 - 4 } & Controls & $4^{*}$ & 26 & & \\
\hline \multirow{2}{*}{ Total } & LDH & 28 & 38 & 0.000 & $5.579(2.208-14.099)$ \\
\cline { 2 - 4 } & Controls & 7 & 53 & & \\
\hline
\end{tabular}

* The continuity corrected chi-square test results.

FT might alter the biomechanics of lumbar segments, but there has been no final conclusion about the association between FT and $\mathrm{LDH}^{5,9,23}$ thus far. Another study also found that FT is associated with LDH at the L5-S1 motion segment but not at the L4-5 level. ${ }^{5}$ In the present study, the authors conclude that FT is associated with LDH at both L4-5 (16/39 in those with LDH and 3/30 in controls, $\mathrm{p}=0.006)$ and L5-S1 (12/27 in those with LDH and 4/30 in controls, $p=0.017$ ). FT may be a result of LDH, especially in older patients with a long history of $\mathrm{LDH}$, but this hypothesis needs to be verified. As all the patients in the present study were adolescents without serious facet joint degeneration, FT was considered to be a risk factor for LDH. A lot of variables could affect the conclusion of the study of the association between FT and LDH, such as the method used to measure the facet joint angle, the definition of FT, and so on, but in the present study the more appropriate type of $\operatorname{control}^{5}$ may be the key factor for the different conclusion.

Trauma was the main cause for adolescent LDH, but it was degeneration for adults with LDH. A finite element analysis found that FT could make the lumbar segment vulnerable to shear force..$^{15} \mathrm{FT}$ may have a different role in the pathology of LDH in adolescents and adults. Murtagh et al. investigated the association between FT and LDH in adults, and found that FT was not a correlative factor for LDH. ${ }^{23}$ Ishihara et al. concluded that FT was a high risk factor for LDH in adolescents, ${ }^{12}$ but Lee et al. did not reach the same conclusion. ${ }^{20}$ The present study, however, did reach the same conclusion as that of Ishihara et al.

Establishing an appropriate control is a crucial matter for a clinical test. Previous researchers used the adjacent segment, which has no disc herniation, as the control, ${ }^{5}$ and they concluded that FT was associated with LDH at L4-5 but not at L5-S1. The different segments in the lumbar spine have different ranges of motion and different roles in lumbar biomechanics, so using the adjacent segment as the control was not strict enough. ${ }^{16}$ In this study, the facet joints in the same segment as the herniated level in asymptomatic volunteers were used as the control. Samesegment controls have greater significance than adjacentsegment controls, and a distinct result was achieved. The age of the control group was not the same as the age of the LDH group, but the facet orientation was not affected by age. The control group was older than the LDH group and had no LDH when they became volunteers for the study, so their facet joints were sufficiently stable to keep them 
from acquiring $\mathrm{LDH}$ in adolescence, and therefore it was a significant control group.

The definition of FT was also an important factor, which could influence the conclusion of the study about the association between FT and LDH. Kunakornsawat et al. ${ }^{19}$ defined FT as a $5^{\circ}$ differential between left and right facet joint angle in the same segment, and they found no exact association between FT and LDH. Karacan et al. ${ }^{14}$ defined FT as the bilateral angle difference greater than 2 intraobserver errors, and they found that FT was more prominent in the LDH group. Kong et al. ${ }^{17}$ defined FT as a $7^{\circ}$ difference between bilateral facet joints in the same segment, and no significant correlation was observed in the study. Ko et al. ${ }^{16}$ defined FT as a difference between the left and right angle of more than $12^{\circ}, 15^{\circ}$, and $12^{\circ}$ at L3-4, L4-5, and L5-S1, respectively. They also did not find an exact association between FT and LDH. A $7^{\circ}$ difference between left and right facet joints was defined as FT, and a difference of more than $15^{\circ}$ was defined as severe FT in the study by Grogan et al. ${ }^{11}$ An exact definition of FT in different lesions would be different for the different biological mechanism. The authors defined FT as a $10^{\circ}$ differential between left and right, because they believe that $10^{\circ}$ is the ideal number for defining FT. A smaller cutoff such as $1^{\circ}$ or $5^{\circ}$ could introduce a measurement bias (whether there is actually tropism or just a measurement error) as well as lead to inclusion of a much larger number of motion segments, while a larger cutoff such as $15^{\circ}$ would be present at very few levels, and Grogan et al. concluded that FT is present both at the L5-S1 level and L4-5 level.

With the advantage of high resolution, MRI has become the most useful tool for diagnosing a lumbar lesion. ${ }^{8}$ Because of the improvement in radiological technology and the development of imaging instruments, MRI could identify the structure of the facet joint and had similar accuracy as a CT scan, ${ }^{10}$ which is considered the best method for measuring the facet joint angle. ${ }^{13,24}$ We obtained satisfactory consistency when we measured the facet angle on MRI compared with the same segment measured on CT before the study, so we measured the facet angle using MRI. Our concern about radiation damage to the 30 volunteers was another reason why our choice was not CT but MRI.

\section{Conclusions}

FT, defined as a $10^{\circ}$ difference between left and right facet joints, was associated with LDH at both the L4-5 and L5-S1 levels in adolescents.

\section{References}

1. Adams MA, Hutton WC: The effect of posture on the role of the apophysial joints in resisting intervertebral compressive forces. J Bone Joint Surg Br 62:358-362, 1980

2. Benifla M, Melamed I, Barrelly R, Aloushin A, Shelef I: Unilateral partial hemilaminectomy for disc removal in a 1-yearold child. J Neurosurg Pediatr 2:133-135, 2008

3. Boden SD, Riew KD, Yamaguchi K, Branch TP, Schellinger D, Wiesel SW: Orientation of the lumbar facet joints: association with degenerative disc disease. J Bone Joint Surg Am 78:403-411, 1996
4. Cassidy JD, Loback D, Yong-Hing K, Tchang S: Lumbar facet joint asymmetry. Intervertebral disc herniation. Spine (Phila Pa 1976) 17:570-574, 1992

5. Chadha M, Sharma G, Arora SS, Kochar V: Association of facet tropism with lumbar disc herniation. Eur Spine J 22:1045-1052, 2013

6. Cyron BM, Hutton WC: Articular tropism and stability of the lumbar spine. Spine (Phila Pa 1976) 5:168-172, 1980

7. Dai LY: Orientation and tropism of lumbar facet joints in degenerative spondylolisthesis. Int Orthop 25:40-42, 2001

8. Eun SS, Lee HY, Lee SH, Kim KH, Liu WC: MRI versus CT for the diagnosis of lumbar spinal stenosis. J Neuroradiol 39:104-109, 2012

9. Farfan HF, Sullivan JD: The relation of facet orientation to intervertebral disc failure. Can J Surg 10:179-185, 1967

10. Freyhardt P, Hartwig T, De Bucourt M, Maurer M, Renz D, Gebauer B, et al: MR-guided facet joint injection therapy using an open 1.0-T MRI system: an outcome study. Eur Radiol 23:3296-3303, 2013

11. Grogan J, Nowicki BH, Schmidt TA, Haughton VM: Lumbar facet joint tropism does not accelerate degeneration of the facet joints. AJNR Am J Neuroradiol 18:1325-1329, 1997

12. Ishihara $H$, Matsui $H$, Osada R, Ohshima H, Tsuji H: Facet joint asymmetry as a radiologic feature of lumbar intervertebral disc herniation in children and adolescents. Spine (Phila Pa 1976) 22:2001-2004, 1997

13. Jarvik JG, Deyo RA: Diagnostic evaluation of low back pain with emphasis on imaging. Ann Intern Med 137:586-597, 2002

14. Karacan I, Aydin T, Sahin Z, Cidem M, Koyuncu H, Aktas I, et al: Facet angles in lumbar disc herniation: their relation to anthropometric features. Spine (Phila Pa 1976) 29:11321136,2004

15. Kim HJ, Chun HJ, Lee HM, Kang KT, Lee CK, Chang BS, et al: The biomechanical influence of the facet joint orientation and the facet tropism in the lumbar spine. Spine J 13:13011308,2013

16. Ko HY, Park BK: Facet tropism in lumbar motion segments and its significance in disc herniation. Arch Phys Med Rehabil 78:1211-1214, 1997

17. Kong MH, He W, Tsai YD, Chen NF, Keorochana G, Do DH, et al: Relationship of facet tropism with degeneration and stability of functional spinal unit. Yonsei Med J 50:624-629, 2009

18. Kumar R, Kumar V, Das NK, Behari S, Mahapatra AK: Adolescent lumbar disc disease: findings and outcome. Childs Nerv Syst 23:1295-1299, 2007

19. Kunakornsawat S, Ngamlamaidt K, Tungsiripat R, Prasartritha T: The relationship of facet tropism to lumbar disc herniation. J Med Assoc Thai 90:1337-1341, 2007

20. Lee DY, Ahn Y, Lee SH: The influence of facet tropism on herniation of the lumbar disc in adolescents and adults. J Bone Joint Surg Br 88:520-523, 2006

21. Lee JY, Ernestus RI, Schröder R, Klug N: Histological study of lumbar intervertebral disc herniation in adolescents. Acta Neurochir (Wien) 142:1107-1110, 2000

22. Martínez-Lage JF, Fernández Cornejo V, López F, Poza M: Lumbar disc herniation in early childhood: case report and literature review. Childs Nerv Syst 19:258-260, 2003

23. Murtagh FR, Paulsen RD, Rechtine GR: The role and incidence of facet tropism in lumbar spine degenerative disc disease. J Spinal Disord 4:86-89, 1991

24. Raskin SP: Degenerative changes of the lumbar spine: assessment by computed tomography. Orthopedics 4:186-195, 1981

25. Revuelta R, De Juambelz PP, Fernandez B, Flores JA: Lumbar disc herniation in a 27 -month-old child. Case report. J Neurosurg 92 (1 Suppl):98-100, 2000

26. Tulsi RS, Hermanis GM: A study of the angle of inclination 
and facet curvature of superior lumbar zygapophyseal facets. Spine (Phila Pa 1976) 18:1311-1317, 1993

27. Wang H, Cheng J, Xiao H, Li C, Zhou Y: Adolescent lumbar disc herniation: experience from a large minimally invasive treatment centre for lumbar degenerative disease in Chongqing, China. Clin Neurol Neurosurg 115:1415-1419, 2013

28. Woo EJ: End-plate measurements as early markers of disc degeneration and herniation. Spine J 13:1418, 2013 (Letter)

29. Yang KH, King AI: Mechanism of facet load transmission as a hypothesis for low-back pain. Spine (Phila Pa 1976) 9:557-565, 1984

\section{Disclosures}

The authors report no conflict of interest concerning the materi- als or methods used in this study or the findings specified in this paper.

\section{Author Contributions}

Conception and design: Zhou. Acquisition of data: Wang. Analysis and interpretation of data: Wang. Drafting the article: Wang. Critically revising the article: Zhou. Reviewed submitted version of manuscript: Zhou. Statistical analysis: Wang. Administrative/ technical/material support: Wang. Study supervision: Zhou.

\section{Correspondence}

Yue Zhou, Department of Orthopedics, Xinqiao Hospital, Third Military Medical University, 183 Xinqiao St., Shapingba District, Chongqing 400037, China. email: happyzhou_vip@163.com. 